\title{
(6) OPEN ACCESS \\ Efficacy and safety of CT-P13 (biosimilar infliximab) in patients with rheumatoid arthritis: comparison between switching from reference infliximab to CT-P13 and continuing CT-P13 in the PLANETRA extension study
}

\author{
Dae Hyun Yoo, ${ }^{1}$ Nenad Prodanovic, ${ }^{2}$ Janusz Jaworski, ${ }^{3}$ Pedro Miranda, ${ }^{4}$ \\ Edgar Ramiterre, ${ }^{5}$ Allan Lanzon, ${ }^{6}$ Asta Baranauskaite, ${ }^{7}$ Piotr Wiland, ${ }^{8}$ \\ Carlos Abud-Mendoza, ${ }^{9}$ Boycho Oparanov, ${ }^{10}$ Svitlana Smiyan, ${ }^{11}$ HoUng Kim, ${ }^{12}$ \\ Sang Joon Lee, ${ }^{12}$ SuYeon Kim, ${ }^{12}$ Won Park ${ }^{13}$
}

\begin{abstract}
Handling editor Tore K Kvien
- Additional material is published online only. To view please visit the journal online (http://dx.doi.org/10.1136/ annrheumdis-2015-208786).

For numbered affiliations see end of article.
\end{abstract}

\section{Correspondence to} Professor Won Park, IN-HA University, School of Medicine, Medicine/Rheumatology, 366, Seohae-Daero, Jung-Gu, Incheon 22332, Republic of Korea; parkwon@inha.ac.kr and Professor Dae Hyun Yoo, Division of Rheumatology, Hanyang University Hospital for Rheumatic Diseases, 222-1 Wangsimni-Ro, Seongdong-Gu, Seoul 04763, Republic of Korea; dhyoo@hanyang.ac.kr

Received 17 October 2015 Revised 7 April 2016 Accepted 9 April 2016 Published Online First 29 April 2016

CrossMark

\section{SLinked}

- http://dx.doi.org/10.1136/ annrheumdis-2015-208783

\footnotetext{
To cite: Yoo DH,

Prodanovic N, Jaworski J,

et al. Ann Rheum Dis

2017;76:355-363.
}

\section{ABSTRACT}

Objectives To assess the efficacy and safety of switching from the infliximab reference product (RP; Remicade) to its biosimilar CT-P13 (Remsima, Inflectra) or continuing CT-P13 in patients with rheumatoid arthritis (RA) for an additional six infusions. Methods This open-label extension study recruited patients with RA who had completed the 54-week, randomised, parallel-group study comparing CT-P13 with RP (PLANETRA; NCT01217086). CT-P13 (3 mg/kg) was administered intravenously every 8 weeks from weeks 62 to 102 . All patients received concomitant methotrexate. Endpoints included American College of Rheumatology 20\% (ACR20) response, ACR50, ACR70, immunogenicity and safety. Data were analysed for patients who received CT-P13 for 102 weeks (maintenance group) and for those who received RP for 54 weeks and then switched to CT-P13 (switch group).

Results Overall, 302 of 455 patients who completed the PLANETRA study enrolled into the extension. Of these, 158 had received CT-P13 (maintenance group) and 144 RP (switch group). Response rates at week 102 for maintenance versus switch groups, respectively, were $71.7 \%$ vs $71.8 \%$ for ACR20, $48.0 \%$ vs $51.4 \%$ for ACR50 and $24.3 \%$ vs $26.1 \%$ for ACR70. The proportion of patients with antidrug antibodies was comparable between groups (week 102: $40.3 \%$ vs $44.8 \%$, respectively). Treatment-emergent adverse events occurred in similar proportions of patients in the two groups during the extension study $(53.5 \%$ and $53.8 \%$, respectively).

Conclusions Comparable efficacy and tolerability were observed in patients who switched from RP to its biosimilar CT-P13 for an additional year and in those who had long-term CT-P13 treatment for 2 years. Trial registration number NCT01571219; Results.

\section{INTRODUCTION}

Infliximab is a human-murine chimeric monoclonal antibody to tumour necrosis factor (TNF). ${ }^{1}$ The introduction of infliximab and other biological drugs into clinical practice has dramatically improved the management of a number of immune-mediated inflammatory diseases, including rheumatoid arthritis (RA). ${ }^{2}$ However, currently available biologics are associated with high costs, ${ }^{3} 4$ which has led to restricted treatment access for patients with RA in several regions. ${ }^{5-9}$

A number of biologics used to treat RA-including originator infliximab (Remicade), hereafter referred to as the reference product (RP)-have reached or are approaching patent expiry in many countries. As a consequence, follow-on biologics (also termed 'biosimilars') are being developed for the treatment of RA. A biosimilar can be defined as a 'biotherapeutic product that is similar in terms of quality, safety, and efficacy to an already licensed reference biotherapeutic product'. ${ }^{10}$ In order to gain approval, it is usually necessary to show that a biosimilar is highly similar to the RP in physicochemical and biological terms. In addition, clinical studies are generally needed to establish statistical equivalence in pharmacokinetics (PK) and efficacy and to characterise biosimilar safety. ${ }^{11-13}$

Since the first approval of a biosimilar by the European Medicines Agency (EMA) in 2006, a number of these agents, including granulocyte colony-stimulating factors and erythropoietins, have become available in Europe. Indeed, the range of therapeutic areas now covered by approved biosimilars is wide and includes cancer, anaemia, neutropenia and diabetes. ${ }^{14}$ Data for these EMA-approved biosimilars consistently show that they provide comparable efficacy and safety relative to their RPs. ${ }^{15-23}$ Recently, CT-P13 (Remsima, Inflectra) - a biosimilar of infliximab RP-became the first monoclonal antibody biosimilar to be approved in Europe for use in all indications held by the infliximab RP. ${ }^{24}$ All major physicochemical characteristics and in vitro biological activities of CT-P13 and the RP, including affinity for both soluble and transmembrane forms of TNF, are highly comparable. ${ }^{24} 25$ Approval of CT-P13 was partly based on findings from two 54-week, multinational, randomised, double-blind, parallel-group studies, which compared CT-P13 and RP in ankylosing spondylitis (AS) and RA Programme 
evaLuating the Autoimmune disease iNvEstigational drug cTp13 in AS patients (PLANETAS) and Programme evaLuating the Autoimmune disease iNvEstigational drug cT-p13 in RA patients (PLANETRA)). These studies demonstrated that CT-P13 and RP are highly comparable in terms of PK, efficacy, immunogenicity and safety in both RA and AS. ${ }^{26-29}$ However, an important unanswered question for prescribing physicians is whether it is possible to switch from RP to CT-P13 in patients with RA without any detrimental effects on safety and efficacy. ${ }^{30}$

Here, we report the findings from an open-label extension of the PLANETRA study. There were two main aims of the extension study: (1) to investigate the efficacy and safety of switching to CT-P13 in patients previously treated with RP for 54 weeks in PLANETRA (hereafter named the 'switch group') and (2) to investigate the longer-term efficacy and safety of extended CT-P13 treatment over 2 years in patients previously treated with CT-P13 in PLANETRA (the 'maintenance group'). To facilitate understanding of the data, the results for the maintenance and switch groups are described both for the main (weeks 0-54) and the extension (weeks 54-102) studies.

\section{PATIENTS AND METHODS}

Full details of the methods of the 54-week, randomised, doubleblind, parallel-group PLANETRA study have been reported previously, ${ }^{26}$ and are described briefly below.

\section{Patients}

PLANETRA recruited patients aged $18-75$ years with active RA for $\geq 1$ year according to the 1987 American College of Rheumatology (ACR) classification criteria. Eligible patients did not respond adequately to $\geq 3$ months of treatment with methotrexate (MTX) and received a stable MTX dose (12.5-25 $\mathrm{mg} /$ week) for $\geq 4$ weeks before screening. Patients who had completed the main 54-week PLANETRA study were offered the opportunity to enter the extension study (ClinicalTrials.gov identifier: NCT01571219) for another 1 year. Those who did not sign a new informed consent for the extension study were excluded. Some of the relevant Ministries of Health $(\mathrm{MoH})$ and ethics committees (ECs) did not approve the extension study, mainly due to the fact that data from the PLANETRA study were not available at the time of EC evaluation. Thus, patients from affected institutions were also excluded.

Additional eligibility criteria applied for this extension study included no major protocol violations in the main study and no new therapy for RA in the extension study. Detailed information on non-participants in the extension study is shown in figure 1.

\section{Study design and treatment}

This open-label, single-arm extension of PLANETRA was conducted in 69 centres in 16 countries. In the main study, patients received nine infusions of CT-P13 (CELLTRION, Incheon, Republic of Korea) or the infliximab RP (Janssen Biotech, Horsham, Pennsylvania, USA). After study treatment in PLANETRA, eligible patients could choose to continue in the extension study. However, patients and physicians continued to be blinded to the treatment that the patient had received during the main study. All patients participating in and completing this extension study received six infusions of CT-P13 from week 62 to week 102. During the whole study period, CT-P13 was administered via $2 \mathrm{~h}$ intravenous infusion at a fixed dose of $3 \mathrm{mg} / \mathrm{kg}$. At the discretion of the investigator, antihistamines were provided 30-60 min prior to infusion of CT-P13. MTX (12.5$25 \mathrm{mg} /$ week; oral or parenteral) and folic acid $(\geq 5 \mathrm{mg} / \mathrm{week}$; oral) were coadministered to all patients throughout the main and extension study periods. All patients provided new written informed consent to enrol into the extension study. The study was conducted according to the principles of the Declaration of Helsinki and International Conference on Harmonisation Good Clinical Practice guidelines.

\section{Study endpoints}

\section{Efficacy}

Efficacy assessments were made at baseline and at weeks 14, 30, 54, 78 and 102. Efficacy endpoints included the proportion of patients meeting ACR20, ACR50 and ACR70 criteria; change from baseline in mean disease activity score in 28 joints (DAS28) and the proportion of patients meeting European League Against Rheumatism (EULAR) response criteria. Additional assessments included the number of tender and swollen joints, patient assessment of pain, patient and physician global assessment of disease activity, the Health Assessment Questionnaire (HAQ), levels of $\mathrm{C}$ reactive protein (CRP), erythrocyte sedimentation rate (ESR) and hybrid ACR score.

\section{Immunogenicity}

The proportion of patients with antidrug antibodies (ADAs) was assessed at baseline and at weeks 14, 30, 54, 78 and 102 using the previously reported method. ${ }^{26} 27$ The neutralising activity of ADAs was also assessed by a flow-through immunoassay method using the Gyros Immunoassay Platform (Gyros AB, Sweden).

\section{Safety}

Treatment-emergent adverse events (TEAEs) were assessed throughout the main and extension studies. Other safety assessments included monitoring of TEAEs of special interest (infusion-related reactions (including hypersensitivity and anaphylactic reaction), tuberculosis (TB), latent TB (defined as a positive conversion of an interferon- $\gamma$ release assay (negative at baseline) with a negative result for chest X-ray examination), serious infection, pneumonia, drug-induced liver injury, vascular disorders and malignancies), vital signs, physical examination findings and clinical laboratory analyses.

\section{Exploratory and post hoc endpoints}

Details of exploratory and post hoc endpoints are given in online supplementary appendix A.

\section{Statistical analyses}

All data were analysed descriptively in the maintenance and switch groups. The populations were predefined in the study protocol and statistical analysis plan for participants of the extension study. The efficacy population included all patients who received at least one dose of study treatment and had at least one efficacy measurement in the extension study. Conservatively, ACR response was analysed using non-responder imputation (NRI) for missing values and presented with 95\% CIs of the response rate using an exact binomial approach from the efficacy population. No imputation of missing values was done for analysis of other efficacy endpoints. The safety population consisted of all patients who enrolled in the study, because they had all received study treatment in the preceding study. Data from the main study period were analysed in participants of the extension study only, not in all patients in the main study. Methods for sensitivity analyses of ACR response and statistical analyses of exploratory and post hoc endpoints are included in online supplementary appendix A. 


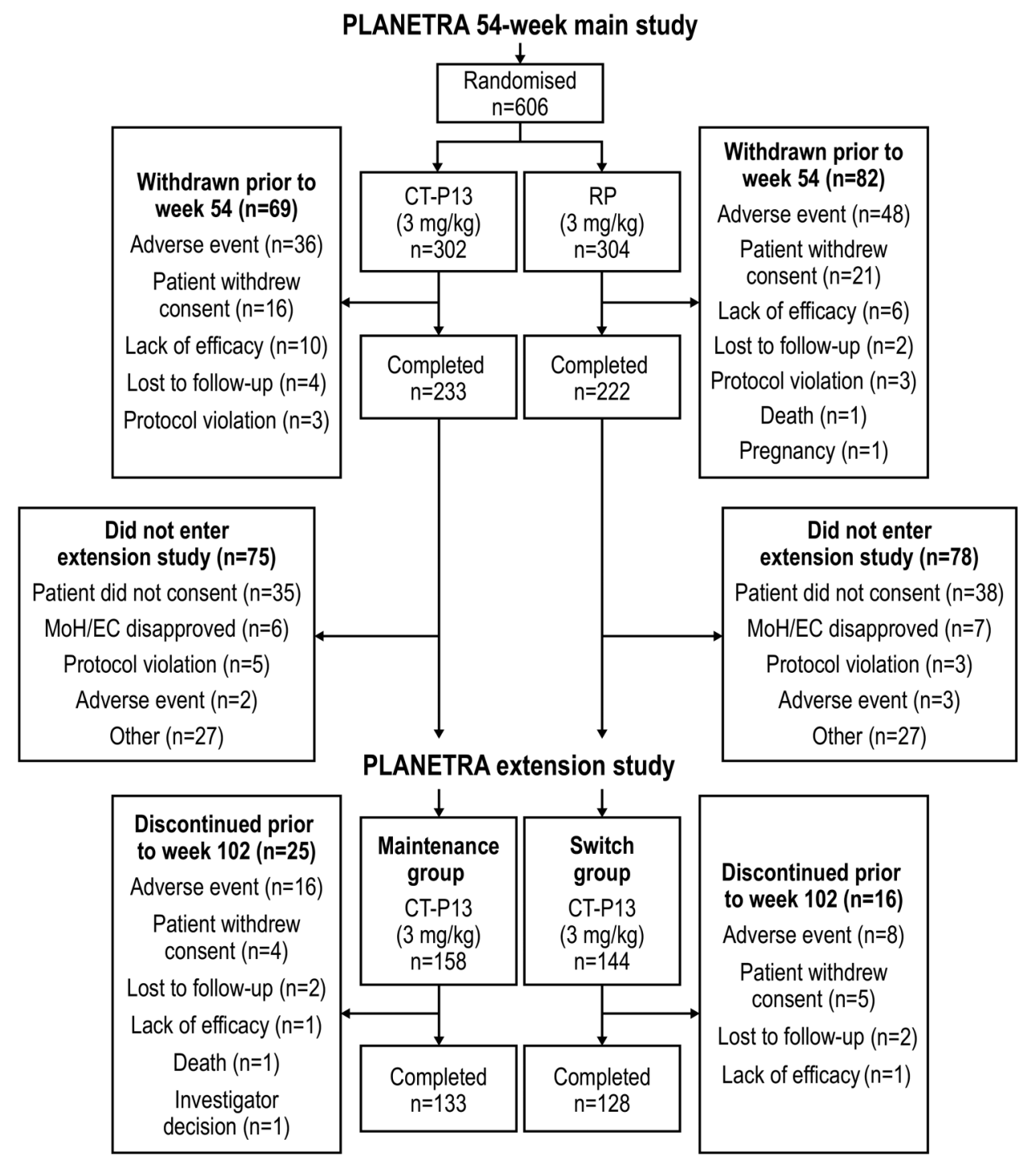

Figure 1 Patient disposition in the PLANETRA extension study. All patients who enrolled in the extension study ( $n=158$ and 144 in the maintenance and switch groups, respectively) were included in the ITT population. EC, ethics committee; ITT, intent-to-treat; MoH, Ministry of Health; RP, reference product.

\section{RESULTS}

\section{Patients}

The first patient visit of the main PLANETRA study and the last visit of the PLANETRA extension were held between November 2010 and July 2013. Of the 455 patients who completed the main PLANETRA study, 302 patients consented to participate in the extension study and were screened under the approval of the appropriate $\mathrm{MoH} / \mathrm{EC}$ (figure 1). Of the 302 screened patients, all were enrolled and 301 were treated. One patient in the maintenance group was enrolled but discontinued due to an adverse event (B-cell lymphoma stage IV) before receiving treatment in the extension study. A total of 158 patients had received CT-P13 in the main study (maintenance group); 144 had received RP (switch group). These patients comprised the intent-to-treat (ITT) population of the extension study. Patient demographics and disease characteristics at baseline and at week 54 of the main study were similar between the two groups (table 1).

In the maintenance and switch groups, respectively, 133 $(84.2 \%)$ and $128(88.9 \%)$ patients completed the extension phase; $25(15.8 \%)$ and $16(11.1 \%)$ patients discontinued over the whole period of the extension study. Reasons for patient withdrawal are shown in figure 1 . The efficacy population of the extension study included 152 patients in the maintenance group and 142 patients in the switch group. Owing to incorrect kits being dispensed, one patient randomly assigned to the RP group received one dose of CT-P13 at week 2 in the PLANETRA main study. Applying a conservative approach, this patient was classified as a member of the CT-P13 group for safety analyses in the main study. Therefore, the safety population of the extension study in the maintenance and switch groups comprised 159 and 143 patients, respectively.

Similar to the ITT population of the extension study, patient demographics and disease characteristics of non-participants in the extension study were also comparable between the CT-P13 and RP groups (see online supplementary appendix B).

\section{Efficacy}

Throughout the extension study, ACR20, ACR50 and ACR70 response rates were maintained, and no differences were evident between the groups at weeks 78 and 102 (figure 2). In the switch group, respective ACR20, ACR50 and ACR70 response 
Table 1 Patient demographics and disease characteristics at baseline and week 54 of patients enrolled in the PLANETRA extension study (ITT population)

\begin{tabular}{|c|c|c|}
\hline Variable* & $\begin{array}{l}\text { Maintenance } \\
\text { groupt }(n=158)\end{array}$ & $\begin{array}{l}\text { Switch group } \neq \\
(n=144)\end{array}$ \\
\hline \multicolumn{3}{|l|}{ Demographics at baseline } \\
\hline Age, years & $50.0(18-73)$ & $49.0(23-74)$ \\
\hline \multicolumn{3}{|l|}{ Gender, $\mathrm{n}(\%)$} \\
\hline Male & $33(20.9)$ & $22(15.3)$ \\
\hline Female & $125(79.1)$ & $122(84.7)$ \\
\hline \multicolumn{3}{|l|}{ Ethnicity, n (\%) } \\
\hline Caucasian & $119(75.3)$ & $105(72.9)$ \\
\hline Black & $1(0.6)$ & $1(0.7)$ \\
\hline Asian & 17 (10.8) & $10(6.9)$ \\
\hline Other & $21(13.3)$ & $28(19.4)$ \\
\hline Height, cm & $163.5(145.5-184.5)$ & $163.0(142.0-188.0)$ \\
\hline Weight, kg & $71.0(43.0-134.0)$ & $68.3(44.3-125.0)$ \\
\hline Body mass index, $\mathrm{kg} / \mathrm{m}^{2}$ & $26.8(17.0-49.8)$ & $25.6(17.3-44.8)$ \\
\hline \multicolumn{3}{|l|}{ Disease characteristics at baseline } \\
\hline DAS28-CRP & $5.8(3.4-8.1)$ & $5.8(2.9-7.9)$ \\
\hline DAS28-ESR & $6.5(4.5-8.4)$ & $6.6(4.1-8.6)$ \\
\hline Swollen joint count (28 joints) & $11.0(3-26)$ & $10.5(2-26)$ \\
\hline Tender joint count (28 joints) & $14.0(3-28)$ & $15.0(3-28)$ \\
\hline $\begin{array}{l}\text { Anti-CCP antibody positive, } \\
\mathrm{n}(\%)\end{array}$ & $122(77.2)$ & $111(77.1)$ \\
\hline IgA RF positive, $\mathrm{n}(\%)$ & $71(44.9)$ & $55(38.2)$ \\
\hline IgM RF positive, $\mathrm{n}(\%)$ & $118(74.7)$ & $103(71.5)$ \\
\hline IgG RF positive, $\mathrm{n}(\%)$ & $90(57.0)$ & $82(57.0)$ \\
\hline $\mathrm{ESR}(\mathrm{mm} / \mathrm{h})$ & $38.0(16.0-138.0)$ & $38.0(28.0-112.0)$ \\
\hline CRP (mg/dL) & $1.0(0.02-9.3)$ & $0.8(0.02-14.0)$ \\
\hline \multicolumn{3}{|l|}{ Serum CRP concentration, $\mathrm{n}(\%)$} \\
\hline$\leq 2 \mathrm{mg} / \mathrm{dL}$ & $110(69.6)$ & $104(72.2)$ \\
\hline$>2 \mathrm{mg} / \mathrm{dL}$ & $47(29.8)$ & $40(27.8)$ \\
\hline \multicolumn{3}{|l|}{ Disease characteristics at week 54} \\
\hline DAS28-CRP & $3.3(1.1-7.0)$ & $3.3(1.1-7.2)$ \\
\hline DAS28-ESR & $4.0(1.1-8.0)$ & $4.0(1.5-7.4)$ \\
\hline Swollen joint count (28 joints) & $2.0(0-17)$ & $2.0(0-15)$ \\
\hline Tender joint count (28 joints) & $3.0(0-28)$ & $3.0(0-26)$ \\
\hline $\begin{array}{l}\text { Anti-CCP antibody positive, } \\
\mathrm{n}(\%)\end{array}$ & $124(78.5)$ & $112(77.8)$ \\
\hline IgA RF positive, n (\%) & $47(29.8)$ & $51(35.4)$ \\
\hline IgM RF positive, $\mathrm{n}(\%)$ & $105(66.5)$ & $98(68.1)$ \\
\hline IgG RF positive, $\mathrm{n}(\%)$ & $81(51.3)$ & $77(53.5)$ \\
\hline ESR $(\mathrm{mm} / \mathrm{h})$ & $25.0(2.0-120.0)$ & $25.0(2.0-110.0)$ \\
\hline CRP (mg/dL) & $0.4(0.01-17.6)$ & $0.4(0.02-27.1)$ \\
\hline \multicolumn{3}{|l|}{ Serum CRP concentration, $\mathrm{n}(\%)$} \\
\hline$\leq 2 \mathrm{mg} / \mathrm{dL}$ & $141(89.2)$ & $128(88.9)$ \\
\hline$>2 \mathrm{mg} / \mathrm{dL}$ & $17(10.8)$ & $14(9.7)$ \\
\hline ACR20 response, $\mathrm{n}(\%)$ & $119(75.3)$ & $111(77.1)$ \\
\hline ACR50 response, $\mathrm{n}(\%)$ & $72(45.6)$ & $72(50.0)$ \\
\hline ACR70 response, $\mathrm{n}(\%)$ & $34(21.5)$ & $34(23.6)$ \\
\hline
\end{tabular}

Data shown in the table were recorded at the baseline and week 54 visits of the preceding 54-week main study.

*Except where indicated otherwise, values are median (range).

tPatients treated with CT-P13 during the 54 weeks of the main study and the 48-week extension study.

¥Patients treated with RP during the 54 weeks of the main study and then switched to CT-P13 during the 48-week extension study.

ACR, American College of Rheumatology; CCP, cyclic citrullinated peptide; CRP, C reactive protein; DAS28, disease activity score in 28 joints; ESR, erythrocyte sedimentation rate; ITT, intent-to-treat; RF, rheumatoid factor; RP, reference product. rates were $77.5 \%, 50.0 \%$ and $23.9 \%$ at week 54 (ie, at the end of RP treatment) and $71.8 \%, 51.4 \%$ and $26.1 \%$ at week 102 (ie, 48 weeks after the last infusion of RP at week 54). In the maintenance group, respective ACR20, ACR50 and ACR70 response rates were $77.0 \%, 46.1 \%$ and $22.4 \%$ at week 54 and $71.7 \%, 48.0 \%$ and $24.3 \%$ at week 102 . In patients who participated in the extension study, the proportion of patients achieving ACR20, ACR50 and ACR70 responses during the main study was also similar between the two groups. In a subgroup analysis performed according to ADA status, the proportion of ADA-negative patients achieving ACR20 was $85.7 \%$ at week 54 and $82.2 \%$ at week 102 in the maintenance group, and $84.7 \%$ at week 54 and $82.8 \%$ at week 102 in the switch group. In comparison, $68.0 \%$ (week 54) and $73.4 \%$ (week 102) of ADA-positive patients in the maintenance group, and $70.6 \%$ and $73.4 \%$ in the switch group achieved ACR20 (see online supplementary appendix C, figure C-1).

No notable differences in other efficacy endpoints were noted between or within the groups at weeks 14, 30, 54, 78 or 102 . The results for DAS28 score change and EULAR response criteria are shown in online supplementary appendix D. The results of assessments of tender and swollen joints, patient assessment of pain, patient and physician global assessment of disease activity, HAQ, levels of CRP, ESR and hybrid ACR score were not different between groups (see online supplementary appendix E).

Sensitivity analyses to compare populations and statistical approaches supported the appearance of sustained efficacy and comparability between the two groups (see online supplementary appendix F). Analyses using the last observation carried forward (LOCF) approach showed similar results as analyses using the NRI approach, both in the maintenance group (ACR20: 74.1\% using LOCF vs 71.7\% using NRI at week 102, respectively) and in the switch group (ACR20: 77.1\% using LOCF vs $71.8 \%$ using NRI at week 102). Analyses of the main study ITT population using the LOCF approach showed relatively low response rates compared with analyses of the extension study ITT population. However, response rates were comparable between the groups and sustained throughout the 2-year study period, both in the extension study ITT population (ACR20: $74.1 \%$ at week 102 vs $75.3 \%$ at week 54 in the maintenance group, $77.1 \%$ vs $77.1 \%$ in the switch group, respectively) and in the main study ITT population (ACR20: $61.6 \%$ at week 102 vs $62.9 \%$ at week 54 in the CT-P13 group, $59.2 \%$ vs $59.9 \%$ in the RP group, respectively). When data for the main study ITT population were analysed using the NRI approach, lower response rates were seen at week 102 than week 54 although rates were comparable between the groups (ACR20: $36.1 \%$ at week 102 vs $57.0 \%$ at week 54 in the CT-P13 group, $33.6 \%$ vs $52.0 \%$ in the RP group).

When remission was measured up to week 102 based on ACR/EULAR criteria (Boolean-based definition and index-based definition (Simple Disease Activity Index (SDAI)), Clinical Disease Activity Index (CDAI), DAS28 and DAS28 low disease activity, the proportion of patients achieving remission or low disease activity was similar between groups throughout the study period (see online supplementary appendix G).

\section{Immunogenicity}

The proportion of patients with ADAs was similar between the maintenance and switch groups at each time point during the main and extension studies (table 2). Almost all patients with a positive ADA result had a positive result for neutralising antibodies $(\mathrm{NAb})$, and the proportion of patients with a positive 
Figure 2 Proportion of patients with rheumatoid arthritis with (A) an ACR20 response, $(B)$ an $A C R 50$ response and (C) an ACR70 response in the maintenance* and switch ${ }^{* *}$ groups of the PLANETRA extension study (efficacy population with non-responder imputation approach). $\mathrm{Cl}$ values are the $95 \% \mathrm{Cls}$ of the treatment difference. *Patients treated with CT-P13 during the 54 weeks of the main study and the 48-week extension study. ${ }^{*}$ Patients treated with reference product during the 54 weeks of the main study and then switched to CT-P13 during the 48-week extension study. ACR, American College of Rheumatology.

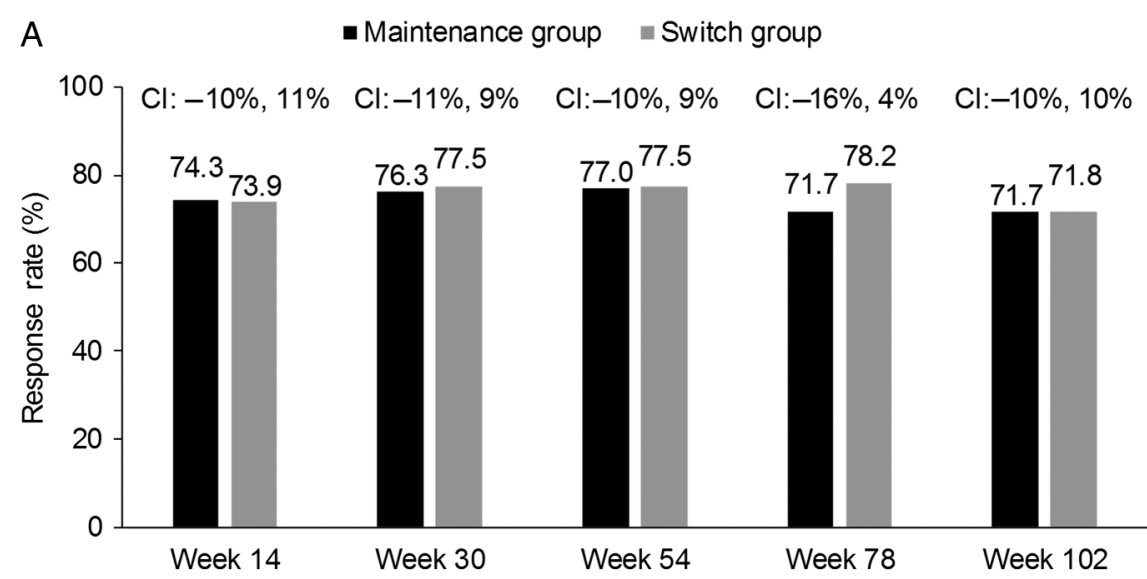

B
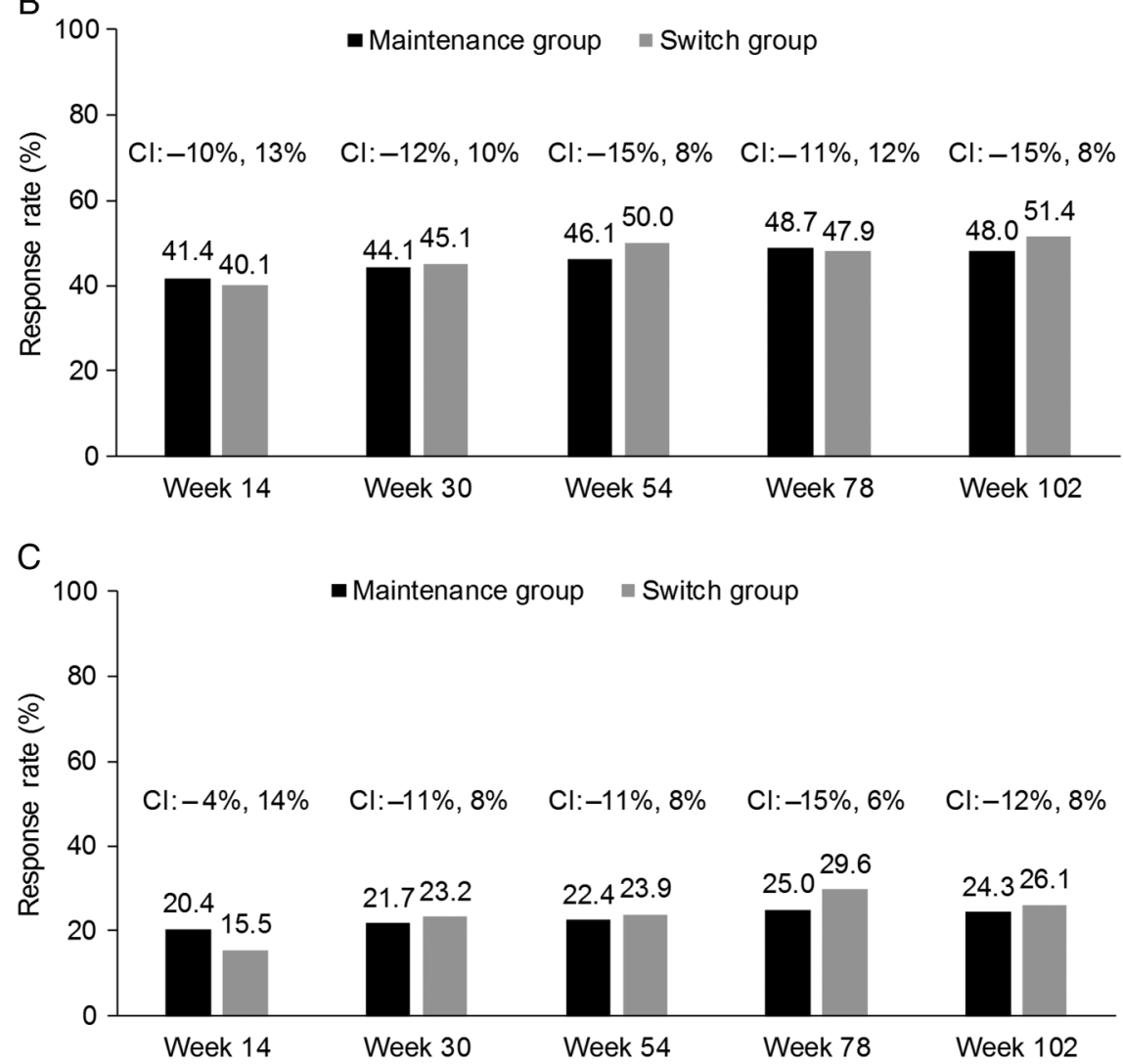

$\mathrm{NAb}$ result was similar between the two groups. The proportion of ADA-positive patients with sustained ADAs was also highly similar between groups $(80.2 \%$ and $80.4 \%$ in the maintenance and switch groups, respectively).

\section{Pharmacodynamics}

In a subgroup analysis performed by ADA status, the mean change from baseline in CRP and ESR was comparable in the maintenance and switch groups at week 54 and week 102 in both ADA-negative and ADA-positive patients (see online supplementary appendix C, table C-1).

\section{Safety}

The proportion of patients who experienced at least one TEAE was comparable between the maintenance group and the switch group (extension study: $53.5 \%(\mathrm{n}=85$ of 159$)$ and $53.8 \%$ $(n=77$ of 143$)$, respectively; main study: $63.5 \%(n=101)$ and $62.2 \%(n=89))$. Rates of TEAEs considered by the investigator to be related to study treatment were also similar between the maintenance and switch groups (extension study: 22.0\% $(\mathrm{n}=35)$ and $18.9 \%(n=27)$; main study: $35.2 \%(n=56)$ and $35.7 \%$ $(n=51))$. The most common treatment-related TEAEs are shown in table 3 .

With respect to serious adverse events (SAEs), these events occurred in the maintenance and switch groups, respectively, in $12(7.5 \%)$ and $13(9.1 \%)$ patients during the extension study, and in $9(5.7 \%)$ and $5(3.5 \%)$ patients during the main study. Treatment-related SAEs occurred in two (1.3\%) and four $(2.8 \%)$ patients in the extension study, respectively, and in two $(1.3 \%)$ and two (1.4\%) patients in the main study (see online supplementary appendix $\mathrm{H})$. TEAEs leading to discontinuation occurred in $16(10.1 \%)$ and $8(5.6 \%)$ patients during the extension study.

During the extension study, 11 (6.9\%) and 4 (2.8\%) patients in the maintenance and switch groups, respectively, reported infusion-related reactions. All were ADA positive and had 
Table 2 Proportion of patients with RA who were positive for ADAs and NAbs in the main study and the extension study (safety population)

\begin{tabular}{l}
$\begin{array}{l}\text { Patients positive for ADAs and NAbs } \\
\text { (n, \%) }\end{array}$ \\
\cline { 2 - 3 } $\begin{array}{l}\text { Maintenance group* } \\
(\mathbf{n}=159)\end{array}$
\end{tabular}

sustained ADAs. Only one patient in the maintenance group experienced anaphylaxis. This patient was ADA positive (see online supplementary appendix C, table C-2). In the main study, infusion-related reactions were reported in $8(5.0 \%)$ and $13(9.1 \%)$ patients in the maintenance and switch groups, respectively. Of these, $4(50.0 \%)$ and 11 (84.6\%) were ADA positive. Two patients reported infusion-related reactions both in the main study and in the extension study period (one patient in each group). Table 4 shows data for all other TEAEs of special interest. No cases of TB were reported during the extension study.

\section{DISCUSSION}

The PLANETRA extension study examined the efficacy and safety of treatment with a maximum of six infusions of CT-P13 in patients with RA previously treated with either CT-P13 (maintenance group) or infliximab RP (switch group) for 54 weeks. Importantly, in the switch group, no notable differences in ACR response rates were observed between week 54 (ie, the last RP treatment) and week 102 (ie, 48 weeks after the last RP infusion). Patients in the maintenance group of this extension study received CT-P13 for a total of 102 weeks. In this cohort, the responses to CT-P13 observed in the main study were sustained during the extension study. In the main parallel-group phase of PLANETRA, ${ }^{26} 27$ ACR responses were broadly comparable with those observed in previous randomised studies of RP up to 54 weeks. ${ }^{31-33}$ The multinational Anti-TNF Trial in Rheumatoid Arthritis with Concomitant Therapy
Table 3 Treatment-related TEAEs that were reported in at least $1 \%$ of patients in either the maintenance group or the switch group (safety population)

\begin{tabular}{|c|c|c|c|}
\hline TEAE, n (\%) & $\begin{array}{l}\text { Maintenance } \\
\text { group* } \\
(n=159)\end{array}$ & $\begin{array}{l}\text { Switch } \\
\text { groupt } \\
(n=143)\end{array}$ & $\begin{array}{l}\text { Total } \\
(n=302)\end{array}$ \\
\hline \multicolumn{4}{|l|}{ Main study period } \\
\hline Infusion-related reaction & $8(5.0)$ & $13(9.1)$ & $21(7.0)$ \\
\hline Abnormal liver function test & $11(6.9)$ & $6(4.2)$ & $17(5.6)$ \\
\hline $\begin{array}{l}\text { Upper respiratory tract } \\
\text { infection }\end{array}$ & $11(6.9)$ & $6(4.2)$ & $17(5.6)$ \\
\hline Latent TB & $8(5.0)$ & $5(3.5)$ & $13(4.3)$ \\
\hline Urinary tract infection & $6(3.8)$ & $6(4.2)$ & $12(4.0)$ \\
\hline Flare in RA activity & $6(3.8)$ & $1(0.7)$ & $7(2.3)$ \\
\hline $\begin{array}{l}\text { Lower respiratory tract } \\
\text { infection }\end{array}$ & $2(1.3)$ & $4(2.8)$ & $6(2.0)$ \\
\hline Anaemia & $1(0.6)$ & $3(2.1)$ & $4(1.3)$ \\
\hline Headache & $2(1.3)$ & $1(0.7)$ & $3(1.0)$ \\
\hline Herpes virus infection & $2(1.3)$ & $1(0.7)$ & $3(1.0)$ \\
\hline Vaginitis & $3(1.9)$ & 0 & $3(1.0)$ \\
\hline Contusion & $2(1.3)$ & 0 & $2(0.7)$ \\
\hline Diarrhoea & $2(1.3)$ & 0 & $2(0.7)$ \\
\hline Psoriasis & $2(1.3)$ & 0 & $2(0.7)$ \\
\hline Fever & 0 & $2(1.4)$ & $2(0.7)$ \\
\hline Rash & 0 & $2(1.4)$ & $2(0.7)$ \\
\hline Rhinitis & 0 & $2(1.4)$ & $2(0.7)$ \\
\hline Uterine haemorrhage & 0 & $2(1.4)$ & $2(0.7)$ \\
\hline \multicolumn{4}{|l|}{ Extension study period } \\
\hline Infusion-related reaction & $11(6.9)$ & $4(2.8)$ & $15(5.0)$ \\
\hline Latent TB & $9(5.7)$ & $4(2.8)$ & $13(4.3)$ \\
\hline $\begin{array}{l}\text { Upper respiratory tract } \\
\text { infection }\end{array}$ & $6(3.8)$ & $3(2.1)$ & $9(3.0)$ \\
\hline $\begin{array}{l}\text { Lower respiratory tract } \\
\text { infection }\end{array}$ & $4(2.5)$ & $4(2.8)$ & $8(2.6)$ \\
\hline Abnormal liver function test & $1(0.6)$ & $4(2.8)$ & $5(1.7)$ \\
\hline Urinary tract infection & $2(1.3)$ & $2(1.4)$ & $4(1.3)$ \\
\hline Bursitis & $2(1.3)$ & 0 & $2(0.7)$ \\
\hline Urticaria & 0 & $2(1.4)$ & $2(0.7)$ \\
\hline
\end{tabular}

*Patients treated with CT-P13 during the 54 weeks of the main study and the 48-week extension study.

tPatients treated with RP during the 54 weeks of the main study and then switched to CT-P13 during the 48-week extension study.

RA, rheumatoid arthritis; RP, reference product; TB, tuberculosis; TEAE, treatment-emergent adverse event.

(ATTRACT) was the pivotal study of MTX plus either RP or placebo in patients with RA. Eligibility criteria for that study were similar to those for PLANETRA. A comparison of the 102-week data presented here with data from the same treatment duration of ATTRACT confirms that ACR response rates in the former were at least comparable with those in ATTRACT (if not higher). ${ }^{34}$ These data support the long-term efficacy of CT-P13 in patients with RA. Further efficacy endpoints-including DAS28-CRP, DAS28-ESR and EULAR-CRP or EULAR-ESR responses-were also maintained from week 54 to 102 in the switch group and were comparable between the maintenance and switch groups at weeks 78 and 102. In addition, the proportion of patients with remission by ACR/EULAR criteria, CDAI, DAS28 and DAS28 low disease activity was also comparable between the two treatment groups during the whole study period. Together, this suggests that there was no detrimental 
Table 4 TEAEs of special interest regardless of relationship to study treatment in the PLANETRA main study and the extension study (safety population)

\begin{tabular}{|c|c|c|}
\hline TEAE, n (\%) & $\begin{array}{l}\text { Maintenance group* } \\
(n=159)\end{array}$ & $\begin{array}{l}\text { Switch group } t \\
(n=143)\end{array}$ \\
\hline \multicolumn{3}{|l|}{ Main study period } \\
\hline Infusion-related reactions & $8(5.0)$ & $13(9.1)$ \\
\hline TB & 0 & 0 \\
\hline Latent TB $\ddagger$ & $12(7.6)$ & $6(4.2)$ \\
\hline Serious infection§ & $2(1.3)$ & $1(0.7)$ \\
\hline Pneumonia§ & $1(0.6)$ & $1(0.7)$ \\
\hline Drug-induced liver injury & 0 & 0 \\
\hline Vascular disorders & $12(7.2)$ & $7(4.9)$ \\
\hline Malignancies & 0 & 0 \\
\hline \multicolumn{3}{|l|}{ Extension study period } \\
\hline Infusion-related reactions & $11(6.9)$ & $4(2.8)$ \\
\hline TB & 0 & 0 \\
\hline Latent TB $\ddagger$ & $11(6.9)$ & $7(4.9)$ \\
\hline Serious infection & $4(2.5)$ & $3(2.1)$ \\
\hline Pneumonia & $1(0.6)$ & 0 \\
\hline Drug-induced liver injury & 0 & 0 \\
\hline Vascular disorders & $4(2.5)$ & $3(2.1)$ \\
\hline Malignancies & $2(1.3)$ & $3(2.1)$ \\
\hline
\end{tabular}

*Patients treated with CT-P13 during the 54 weeks of the main study and the 48-week extension study.

tPatients treated with RP during the 54 weeks of the main study and then switched to CT-P13 during the 48-week extension study.

¥There were three patients (two in the maintenance group, one in the switch group) with three events of latent TB, which were reported both in the main study and in the extension study; this was because all three events started during week 62 (part of the end-of-study period of the main study).

§There was one patient in the maintenance group with a serious AE of pneumonia, which was included as a 'Serious infection' and 'Pneumonia' during the main study. $A E$, adverse event; $R P$, reference product; $T B$, tuberculosis; TEAE, treatment-emergent adverse event.

impact on efficacy of switching from RP to CT-P13 in patients with RA. Sensitivity analyses supported the sustained efficacy and comparability observed between the two groups. A multiple analysis approach, using LOCF and NRI methods, reported similar results, both in the maintenance group and in the switch group. Analyses of the main study ITT population and the extension study ITT population using the LOCF approach showed comparable and sustained outcomes throughout the 2 -year study period. When analysed using the NRI approach, response rates at week 78 and week 102 in the main study ITT population were lower than when the LOCF approach was used. However, response rates were similar in both groups regardless of approach. Variations in response rates that occurred according to the analysis method were caused by the fact that some responders in the main study did not participate in the extension study (figure 1). In order to further understand the influence of non-participants in the extension study, patient demographics at baseline, disease characteristics at baseline and week 54 (see online supplementary appendix B) and ACR20 responses according to ADA status at week 54 (see online supplementary appendix I) were further analysed for this population. The results support the comparability between CT-P13 and RP groups, even for non-participants.

CT-P13 was well tolerated during the extension study and displayed a long-term safety profile consistent with that of infliximab RP. ${ }^{34} 35$ There was no noticeable difference in the safety profile before and after switching. After week 54 of the main study, the incidence of TEAEs, drug-related TEAEs or SAEs was similar between the maintenance and switch groups. The incidence of all potential infusion-related reactions did not increase when patients previously treated with RP were switched to CT-P13. During the extension study, 11 (6.9\%) patients in the maintenance group and $4(2.8 \%)$ patients in the switch group experienced infusion-related reactions. Infusion-related reactions were reported for $8(5.0 \%)$ patients in the maintenance group and $13(9.1 \%)$ patients in the switch group in the main study (ie, before the switch). Most of these events were of mild to moderate severity.

In terms of immunogenicity, the proportion of patients with ADAs remained stable and did not increase between weeks 54 and 102 in either group, although only qualitative analysis of ADA data was performed. In a similarly designed extension of the PLANETAS study, the proportion of patients with AS with ADAs also did not increase consistently. ${ }^{36}$ In the PLANETRA extension study, the ADA rate was comparable between the maintenance and switch groups at 102 weeks. The proportion of patients with sustained ADAs during the entire study period was also highly similar between groups. Similarly, in the PLANETAS extension study, the number of patients with AS with sustained ADAs was also similar between maintenance and switch groups. These data indicate no detrimental effect on immunogenicity when changing from RP to CT-P13, at least for the first six infusions. There was no analysis for IgG4.

Concomitant use of MTX has been shown to reduce the immunogenicity of infliximab. ${ }^{37}$ In PLANETRA, MTX was coadministered throughout the study. Given that the initial and most recent doses of MTX were similar between the maintenance and switch groups (initial dose: 15.47 vs $15.51 \mathrm{mg} /$ week; most recent dose: 15.52 vs $15.40 \mathrm{mg} /$ week), it can be assumed that the effect of MTX on the development of ADAs was also similar between both groups. ADAs to infliximab are associated with a reduced clinical response to this drug, as well as to infusion-related reactions and other unwanted effects. ${ }^{38} \quad 39$ Compared with ADA-negative patients, ADA-positive patients in our study had lower ACR20 response rates and higher levels of CRP and ESR. Such trends were comparable in both the maintenance and switch groups. All of the patients reporting infusion-related reactions were ADA positive in both groups. These results suggest that the effects of switching from RP to CT-P13 did not influence the impact of ADAs.

The findings from the PLANETRA extension study indicate that there are no harmful effects on efficacy, safety or immunogenicity associated with switching from RP to CT-P13 in patients with RA. Similarly, no detrimental effects of switching were observed in an extension of the PLANETAS study performed in patients with AS. ${ }^{36}$ The current results are also aligned with those observed in switching studies with other biosimilars that have been approved by the EMA, which has stringent guidelines relating to the regulation of these types of agents. Switching data from a number of randomised and nonrandomised trials consistently show that detrimental effects of switching between reference biologics and their EMA-approved biosimilars are unlikely to happen. ${ }^{18} 40-45$

The current extension study was not formally designed to evaluate the non-inferiority or equivalence of switching to CT-P13 from RP versus continual CT-P13 treatment. In this respect, a randomised, double-blind, phase IV study has been initiated in Norway ('NOR-SWITCH'; ClinicalTrials.gov identifier: NCT02148640) to formally examine the switchability of CT-P13 in a variety of indications. Additionally, a comprehensive pharmacovigilance programme by the manufacturers of CT-P13 is also ongoing. These postmarketing surveillance and 
registry studies will monitor the safety of CT-P13 in patients with AS, RA and other inflammatory diseases who have switched from RP.

\section{CONCLUSIONS}

This multinational, open-label extension study demonstrated that in patients with RA receiving MTX, switching from RP to CT-P13 was not associated with any detrimental effects on efficacy, immunogenicity or safety. Additionally, this study demonstrated that CT-P13 remained efficacious and well tolerated over a 2-year treatment period.

\author{
Author affiliations \\ ${ }^{1}$ Hanyang University Hospital for Rheumatic Diseases, Seoul, Republic of Korea \\ ${ }^{2}$ Clinical Center Banja Luka, Banja Luka, Bosnia \\ ${ }^{3}$ Reumatika Centrum Reumatologi, Warszawa, Poland \\ ${ }^{4}$ Universidad de Chile and Centro de Estudios Reumatologicos, Santiago de Chile, \\ Chile \\ ${ }^{5}$ Brokenshire Memorial Hospital, Davao City, Philippines \\ ${ }^{6}$ Mary Mediatrix Medical Center, Batangas, Philippines \\ ${ }^{7}$ Lithuanian University of Health Sciences, Kaunas, Lithuania \\ ${ }^{8}$ Medical University of Wroclaw, Wroclaw, Poland \\ ${ }^{9}$ Hospital Central and Faculty of Medicine, Universidad Autónoma de San Luis \\ Potosí, San Luis Potosí, Mexico \\ ${ }^{10}$ Military Medical Academy, Sofia, Bulgaria \\ ${ }^{11}$ I.Ya. Horbachevsky Ternopil State Medical University, Municipal Institution of \\ Ternopil Regional Council "Ternopil University Hospital", Ternopil, Ukraine \\ ${ }^{12}$ CELLTRION, Incheon, Republic of Korea \\ ${ }^{13}$ IN-HA University, School of Medicine, Medicine/Rheumatology, Incheon, Republic \\ of Korea
}

Acknowledgements The authors wish to thank the patients and study personnel who made this trial possible and the PLANETRA study investigators-Bosnia: Mulic Bacic S; Bulgaria: Kadinov V, Rashkov R, Toncheva A; Chile: Arriagada Herrera M, Barria Negron L, Goecke Sariego I; Colombia: Chalem M, Tobias Arteaga E, Abello Banfi M; Italy: Cutolo M; Latvia: Andersone D, Saleniece S, Saulite-Kandevica D; Lithuania: Bukauskiene L, Kausiene R, Smilgiene V, Stropuviene S; Mexico: Araiza R, Cons Molina F, Morales-Torres J, Pacheco-Tena C, Xibille D, Gutierrez-Ureña S; Peru: Calvo A, Vidal Neira L, Morales Olazabal L; Philippines: Amante EJ, Baes R, Eullaran R, Tan P, Tee M; Poland: Brzezicki J, Brzosko M, Daniluk S, Klimiuk P, Piotrowski M, Racewicz A, Ruzga Z, Jeka S, Hrycaj P; Romania: Bojinca VC, Cristei D,

lanuli-Arvunescu MA, Pavel M, Rednic S; Slovakia: Krpciar M, Zlnay D; Spain: Blanco Garcia F, Gómez Centeno A; UK: Adebajo A, Byrne P; Ukraine: Gnylorybov A, Hospodarskyy I, Yagensky A, Yatsyshyn R, Lysenko G, Kovalenko V, Shevchuk S; USA: Ahn C. Editorial support (writing assistance, assembling tables and figures, collating author comments, grammatical editing and referencing) was provided by Ryan Woodrow (Aspire Scientific, Bollington, UK) and was funded by CELLTRION Healthcare Co (Incheon, Republic of Korea).

Contributors DHY, WP, HUK, SJL and SYK were involved in the conception and design of the study and/or the analysis and interpretation of data, drafting of the manuscript and revising it critically for important intellectual content and final approval of the version to be published. NP, JJ, PM, ER, AL, AB, PW, CA-B, BO and SS were involved in the acquisition of data, drafting of the manuscript and revising it critically for important intellectual content and final approval of the version to be published.

Funding This study was funded by CELLTRION Inc. The sponsor participated in study design, in the collection, analysis and interpretation of study data and in reviewing drafts of the manuscript. The final decision to submit the manuscript was made by the authors.

Competing interests DHY and WP: consultation for CELLTRION. AB reports personal fees from Abbvie and grants from Samsung Bioepis and Abbvie, outside the submitted work; HUK, SJL and SYK are full-time employees of CELLTRION.

Patient consent Obtained.

Ethics approval Study protocols, consent forms and other written information were approved by the relevant $\mathrm{MoH}$, each site's institutional review board and independent EC for each study centre.

Provenance and peer review Not commissioned; externally peer reviewed.

Data sharing statement All data available for this paper are included in the manuscript and online supplementary appendices.

Open Access This is an Open Access article distributed in accordance with the Creative Commons Attribution Non Commercial (CC BY-NC 4.0) license, which permits others to distribute, remix, adapt, build upon this work non-commercially, and license their derivative works on different terms, provided the original work is properly cited and the use is non-commercial. See: http://creativecommons.org/ licenses/by-nc/4.0/

\section{REFERENCES}

1 Maini R, St Clair EW, Breedveld F, et al. Infliximab (chimeric anti-tumour necrosis factor alpha monoclonal antibody) versus placebo in rheumatoid arthritis patients receiving concomitant methotrexate: a randomised phase III trial. ATTRACT Study Group. Lancet 1999;354:1932-9.

2 Kuek A, Hazleman BL, Ostör AJ. Immune-mediated inflammatory diseases (IMIDs) and biologic therapy: a medical revolution. Postgrad Med J 2007;83:251-60.

3 Modena V, Bianchi G, Roccatello D. Cost-effectiveness of biologic treatment for rheumatoid arthritis in clinical practice: an achievable target? Autoimmun Rev 2013;12:835-8

4 Nurmohamed MT, Dijkmans BA. Efficacy, tolerability and cost effectiveness of disease-modifying antirheumatic drugs and biologic agents in rheumatoid arthritis. Drugs 2005;65:661-94.

5 Putrik P, Ramiro S, Kvien TK, et al. Inequities in access to biologic and synthetic DMARDs across 46 European countries. Ann Rheum Dis 2014;73:198-206.

6 Fischer MA, Polinski JM, Servi AD, et al. Prior authorization for biologic disease-modifying antirheumatic drugs: a description of US Medicaid programs. Arthritis Rheum 2008;59:1611-17.

7 Pease C, Pope JE, Truong D, et al. Comparison of anti-TNF treatment initiation in rheumatoid arthritis databases demonstrates wide country variability in patient parameters at initiation of anti-TNF therapy. Semin Arthritis Rheum 2011;41:81-9.

8 Sokka T, Kautiainen H, Pincus T, et al. Disparities in rheumatoid arthritis disease activity according to gross domestic product in 25 countries in the QUEST-RA database. Ann Rheum Dis 2009;68:1666-72.

9 Desai RJ, Rao JK, Hansen RA, et al. Predictors of treatment initiation with tumor necrosis factor-alpha inhibitors in patients with rheumatoid arthritis. J Manag Care Pharm 2014;20:1110-20.

10 World Health Organization, Expert Committee on Biological Standardization. Guidelines on evaluation of similar biotherapeutic products (SBPs). 2009. http:// www.who.int/biologicals/areas/biological_therapeutics/BIOTHERAPEUTICS_FOR_ WEB_22APRIL2010.pdf (accessed 4 Apr 2016).

11 European Medicines Agency. Committee for Medicinal Products for Human Use (CHMP). Guideline on Similar Biological Medicine Products (CHMP/437/04 Rev 1). 23 October 2014. http://www.ema.europa.eu/docs/en_GB/document_library/ Scientific guideline/2014/10/WC500176768.pdf (accessed 4 Apr 2016).

12 U.S. Department of Health and Human Services; Food and Drug Administration; Center for Drug Evaluation and Research (CDER); Center for Biologics Evaluation and Research (CBER). Scientific Considerations in Demonstrating Biosimilarity to a Reference Product. Guidance for Industry. April 2015. http://www.fda.gov/ downloads/Drugs/GuidanceComplianceRegulatoryInformation/Guidances/ UCM291128.pdf (accessed 4 Apr 2016).

13 Feagan $B G$, Choquette $D$, Ghosh $S$, et al. The challenge of indication extrapolation for infliximab biosimilars. Biologicals 2014;42:177-83.

14 Generics and Biosimilars Initiative. Biosimilars approved in Europe. 2016. http:// www.gabionline.net/Biosimilars/General/Biosimilars-approved-in-Europe (accessed 4 Apr 2016).

15 Horl WH, Locatelli F, Haag-Weber M, et al. Prospective multicenter study of HX575 (biosimilar epoetin-alpha) in patients with chronic kidney disease applying a target hemoglobin of 10-12 g/dl. Clin Nephrol 2012;78:24-32.

16 Krivoshiev S, Todorov VV, Manitius J, et al. Comparison of the therapeutic effects of epoetin zeta and epoetin alpha in the correction of renal anaemia. Curr Med Res Opin 2008:24:1407-15.

17 Krivoshiev S, Wizemann V, Czekalski S, et al. Therapeutic equivalence of epoetin zeta and alfa, administered subcutaneously, for maintenance treatment of renal anemia. Adv Ther 2010;27:105-17.

18 Davis-Ajami ML, Wu J, Downton K, et al. Epoetin zeta in the management of anemia associated with chronic kidney disease, differential pharmacology and clinical utility. Biologics 2014;8:155-67.

19 Haag-Weber M, Eckardt KU, Horl WH, et al. Safety, immunogenicity and efficacy of subcutaneous biosimilar epoetin-alpha (HX575) in non-dialysis patients with renal anemia: a multi-center, randomized, double-blind study. Clin Nephrol 2012;77:8-17.

20 Gascon P. Presently available biosimilars in hematology-oncology: G-CSF. Target Oncol 2012;7(Suppl 1):S29-34.

21 del Giglio A, Eniu A, Ganea-Motan D, et al. XM02 is superior to placebo and equivalent to Neupogen in reducing the duration of severe neutropenia and the incidence of febrile neutropenia in cycle 1 in breast cancer patients receiving docetaxel/doxorubicin chemotherapy. BMC Cancer 2008;8:332.

22 Engert A, Griskevicius L, Zyuzgin Y, et al. XM02, the first granulocyte colony-stimulating factor biosimilar, is safe and effective in reducing the duration of severe neutropenia and incidence of febrile neutropenia in patients with non-Hodgkin lymphoma receiving chemotherapy. Leuk Lymphoma 2009;50:374-9. 
23 Heinemann L, Hompesch M. Biosimilar insulins: how similar is similar? J Diabetes Sci Technol 2011;5:741-54.

24 European Medicines Agency. Committee for Medicinal Products for Human Use (CHMP). Assessment report: Remsima (infliximab). 2013. http://www.ema.europa. eu/docs/en_GB/document_library/EPAR_-_Public_assessment_report/human/ 002576/WC500151486.pdf (accessed 4 Apr 2016).

25 Jung SK, Lee $\mathrm{KH}$, Jeon JW, et al. Physicochemical characterization of Remsima $®$. mAbs 2014:6:1163-77.

26 Yoo DH, Hrycaj P, Miranda P, et al. A randomised, double-blind, parallel-group study to demonstrate equivalence in efficacy and safety of CT-P13 compared with innovator infliximab when coadministered with methotrexate in patients with active rheumatoid arthritis: the PLANETRA study. Ann Rheum Dis 2013:72:1613-20.

27 Yoo DH, Racewicz A, Brzezicki J, et al. A phase III randomized study to evaluate the efficacy and safety of CT-P13 compared with reference infliximab in patients with active rheumatoid arthritis: 54-week results from the PLANETRA study. Arthritis Res Ther 2016:18:82.

28 Park W, Hrycaj P, Jeka S, et al. A randomised, double-blind, multicentre, parallel-group, prospective study comparing the pharmacokinetics, safety, and efficacy of CT-P13 and innovator infliximab in patients with ankylosing spondylitis: the PLANETAS study. Ann Rheum Dis 2013;72:1605-12.

29 Park W, Yoo DH, Jaworski J, et al. Comparable long-term efficacy, as assessed by patient-reported outcomes, safety and pharmacokinetics, of CT-P13 and reference infliximab in patients with ankylosing spondylitis: 54-week results from the randomized, parallel-group PLANETAS study. Arthritis Res Ther 2016;18:25.

30 Tóthfalusi L, Endrényi L, Chow SC. Statistical and regulatory considerations in assessments of interchangeability of biological drug products. Eur J Health Econ 2014;15 (Suppl 1):S5-11.

31 St Clair EW, van der Heijde DM, Smolen JS, et al. Combination of infliximab and methotrexate therapy for early rheumatoid arthritis: a randomized, controlled trial. Arthritis Rheum 2004;50:3432-43.

32 Schiff M, Keiserman M, Codding C, et al. Efficacy and safety of abatacept or infliximab vs placebo in ATTEST: a phase III, multi-centre, randomised, double-blind, placebo-controlled study in patients with rheumatoid arthritis and an inadequate response to methotrexate. Ann Rheum Dis 2008;67:1096-103.

33 Lipsky PE, van der Heijde DM, St Clair EW, et al. Infliximab and methotrexate in the treatment of rheumatoid arthritis. Anti-Tumor Necrosis Factor Trial in Rheumatoid Arthritis with Concomitant Therapy Study Group. N Engl J Med 2000;343:1594-602.
34 Maini RN, Breedveld FC, Kalden JR, et al. Sustained improvement over two years in physical function, structural damage, and signs and symptoms among patients with rheumatoid arthritis treated with infliximab and methotrexate. Arthritis Rheum 2004;50:1051-65.

35 Braun J, Deodhar A, Dijkmans B, et al. Efficacy and safety of infliximab in patients with ankylosing spondylitis over a two-year period. Arthritis Rheum 2008;59:1270-8.

36 Park W, Woo DH, Miranda P, et al. Efficacy and safety of switching from reference infliximab to CT-P13 compared with maintenance of CT-P13 in ankylosing spondylitis: 102-week data from the PLANETAS extension study. Ann Rheum Dis 2017:76:346-54.

37 Maini RN, Breedveld FC, Kalden JR, et al. Therapeutic efficacy of multiple intravenous infusions of anti-tumor necrosis factor alpha monoclonal antibody combined with low-dose weekly methotrexate in rheumatoid arthritis. Arthritis Rheum 1998:41:1552-63.

38 Plasencia C, Pascual-Salcedo D, Nuño L, et al. Influence of immunogenicity on the efficacy of long-term treatment of spondyloarthritis with infliximab. Ann Rheum Dis 2012;71:1955-60.

39 Baert F, Noman M, Vermeire $S$, et al. Influence of immunogenicity on the long-term efficacy of infliximab in Crohn's disease. $N$ Engl J Med 2003;348:601-8.

40 Haag-Weber $M$, Vetter $A$, Thyroff-Friesinger $U$, et al. Therapeutic equivalence, long-term efficacy and safety of HX575 in the treatment of anemia in chronic renal failure patients receiving hemodialysis. Clin Nephrol 2009;72:380-90.

41 Wizemann V, Rutkowski B, Baldamus C, et al. Comparison of the therapeutic effects of epoetin zeta to epoetin alfa in the maintenance phase of renal anaemia treatment. Curr Med Res Opin 2008;24:625-37.

42 Więcek A, Ahmed I, Scigalla P, et al. Switching epoetin alfa and epoetin zeta in patients with renal anemia on dialysis: posthoc analysis. Adv Ther 2010;27:941-52

43 Lubenau H, Bias P, Maly AK, et al. Pharmacokinetic and pharmacodynamic profile of new biosimilar filgrastim XM02 equivalent to marketed filgrastim Neupogen: single-blind, randomized, crossover trial囚. BioDrugs 2009;23:43-51.

44 Verpoort K, Möhler TM. A non-interventional study of biosimilar granulocyte colony-stimulating factor as prophylaxis for chemotherapy-induced neutropenia in a community oncology centre. Ther Adv Med Oncol 2012;4:289-93.

45 Flodmark $C E$, Lilia $\mathrm{K}$, Woehling $\mathrm{H}$, et al. Switching from originator to biosimilar human growth hormone using dialogue teamwork: single-center experience from Sweden. Biol Ther 2013:3:35-43. 